\title{
Patient's perception of Nigerian physiotherapists as supplementary prescribers
}

\author{
Onigbinde Ayodele Teslim ${ }^{1}$, Oyedemi Oluwapelumi Jeremiah ${ }^{1}$, Tarimo Nesto ${ }^{2}$, Mukoka Grace ${ }^{3}$ \\ ${ }^{1}$ Department of Medical Rehabilitation, College of Health Sciences, Obafemi Awolowo University, Ile-Ife, Osun State, Nigeria \\ ${ }^{2}$ Department of Physiotherapy, Malawi Against Physical disabilities, P. O. Box 256, Blantyre, Malawi \\ ${ }^{3}$ Physiotherapy department, Department of Physiotherapy, College of Medicine, University of Malawi, Blantyre, Malawi
}

\section{Email address:}

ayotesonigbinde@yahoo.co.uk (A. T. Onigbinde)

\section{To cite this article:}

Onigbinde Ayodele Teslim, Oyedemi Oluwapelumi Jeremiah, Tarimo Nesto, Mukoka Grace. Patient's Perception of Nigerian Physiotherapists as Supplementary Prescribers. American Journal of Health Research. Special Issue: Supplementary Prescribing in Nigeria: A Needy Concept to Promote Clinical Physiotherapy Practice. Vol. 2, No. 5-1, 2014, pp. 6-11. doi: 10.11648/j.ajhr.s.2014020501.12

\begin{abstract}
In supplementary prescription (SP) of drugs; patient must consent and ascent to clinical management plans (CMP) and this is the principle of shared decision making (SDM). Shared decision making is a modern care ideology being used to promote effective treatment of patients. If physiotherapists are to become supplementary prescribers (SPs) it is important to seek patient's opinion as they are also expected to be involved in drawing the CMP. The primary aim of this study was to investigate the opinion of Nigerian patients on enlistment and legislation of physiotherapists as supplementary prescribers. A structured and self-administered questionnaire was used to seek the opinion of 240 patients. They were selected from purposively selected health institutions in Nigeria. The data were analyzed using descriptive statistics of frequency, percentage and non-parametric inferential statistics (chi-square). A significant number of patients opined that prescription of drugs should not be restricted to medical doctors alone $\left(\mathrm{X}^{2}=193.67, \mathrm{P}<0.001\right)$. One hundred and ninety four $(81.17 \%)$ participants supported the enactment of policies that will recognize physiotherapists as SPs. Similarly, a significant number of patients opined that physiotherapist should only prescribe oral drugs at the chronic stage of diseases $\left(\mathrm{X}^{2}=35.53, \mathrm{P}<0.001\right)$. Majority opined that supplementary prescribing will reduce waiting time in hospital $(92.89 \%)$, reduce burden on medical doctors $(94.48 \%)$; and increase accessibility and timely intervention of medical care $(94.15 \%)$. In conclusion, most patients opined that Nigeria physiotherapists should be allowed to become supplementary prescribers of relevant oral drugs because of the enormous benefits to patient care. Also, an enactment should be made to protect them against litigations.
\end{abstract}

Keywords: Supplementary Prescription, Patients, Physiotherapists, Medications, Enlistment

\section{Introduction}

There has been paradigm unrelenting transformation of boundaries in the statutory roles of allied health professions, creating new roles and expanding the existing traditional roles; and this is a strategic approach towards improving health care [1]. Inter-disciplinary skills, adequate knowledge and experience of health professionals are required to achieve this modernization [2]. The British Medical Association in 1998 observed that previous health professional relationships were in-appropriate and could not meet the demand of modern day clinical practice [3]. This culminated into nonmedical prescription of drugs by specially trained health professionals such as nurses, pharmacists, radiologist and physiotherapists, and this has been tagged as a 'leading ideology' of modern medical care $[4,5,6,7]$.

The patient-centered health care is now the dominant paradigm in health service delivery [4]. Shared decisionmaking (SDM) has been reported severally to make patients more secured, have a stronger sense of commitment to recover, increase quality of care and improved self-efficacy coupled with increased self-management behaviors $[8,9,10,11,12,13]$.

In Australia, Salisbury and Sullivan observed that 40 per cent of physiotherapists prescribe drugs daily, although, majority had approval from physician [14]. However, more than 50 per cent of those physiotherapists had no formal training except the deficient pharmacology training during undergraduate education. Most physiotherapists have poor pharmacology knowledge in clinical practice because they 
did not have opportunity to practice prescription of what was acquired during undergraduate training [15]. Currently in the UK, physiotherapists had been legislated to advance from being supplementary to independent prescribers [16]. In order to achieve standards, intending non-medic prescribers were trained for safe and effective prescribing [16]. In Nigeria, most physiotherapists desired to be supplementary prescribers and were also willing to improve their pharmacology knowledge and take up responsibilities attached to SP [17]. The inclusion of drug therapy is very crucial as an adjunct to effective treatment in practice of physiotherapy [18].

The main concept of supplementary prescribing, the prescribing 'partnership', must be explained to the patient by the prescriber and the consent, either verbal or written must be recorded in the CMP prior to entering into a prescribing agreement [19]. Also, considering importance of patients in clinical auditing, it is important to investigate the opinion of patients on physiotherapists assuming the role of supplementary prescribers. The primary objective of this study was to investigate the opinion of patients on the desire of physiotherapists to include supplementary prescription to their statutory roles.

\section{Materials and Method}

\subsection{Study Settings}

The settings comprised 5 University Teaching hospitals, 1 national orthopeadic hospital, 2 state hospitals and 3 private clinics located at South west of Nigeria.

\subsection{Sample and Sampling Techniques}

Respondents were 240 patients and they were recruited using the sample of convenience technique at the purposively selected health institutions. Patients who had experienced physiotherapy interventions for at least 5 treatment sessions, and were willing to participate were recruited for the study. Patients that could not read nor write, under the age of 18 and had no relative to interpret the questionnaire were excluded from the study.

\subsection{Sample Size Determination}

We determined a sample size of 250 patients for this study with a $6 \%$ margin error based on assumption that the response rate would be $60 \%$ [20]. The assumed response rate was the consideration that some patients might be illiterate and might also not have relatives who would be able to appropriately interpret the questions. Only 240 patients could meet the inclusion criteria at the time of the study.

\subsection{Research Design}

The study was a quantitative cross-sectional survey.

\subsection{Instrument}

A structured and self-administered structured questionnaire was used in obtaining information for this study. A pilot study using a draft of the questionnaire was conducted among 3 experienced physiotherapists who had at least 15 years of experience in clinical research; they evaluated the questions for viability, simplicity and precision. They made corrections and ascertained that the questionnaire reflected the major focus, concept and objectives of the study [21]. To allow for respondents' differing educational background, the questions were kept as simple as possible in YES and NO format.

The questionnaire was divided into two sections; namely A and B. Section A sought for information on demography and academic related data, diagnosis and opinion on medications. Section B inquired about opinion on government enactment of policies and perceptions on likely benefits of having physiotherapists as supplementary prescribers of relevant medications.

\subsection{Procedure}

Ethical approval was granted by the Health Research and Ethics Committee (HREC) of ObafemiAwolowo University Teaching Hospital Complex (OAUTHC), Ile-Ife, Osun State, Nigeria. Heads of departments of the study settings also granted permission for the study. Each patient willing to participate signed a consent form prior to being administered the questionnaire. In order to maintain anonymity, subjects' name and address were not requested for in the questionnaire. All respondents filled the questionnaire instantly and returned it immediately, however, there was no time restriction to complete the questionnaire.

\subsection{Data Analysis}

The copies of the questionnaire were labeled sequentially, collated and entered into SPSS, version 17 in a private and password protected computer to restrict accessibility of none members of the research team. A descriptive statistics of frequency, percentages, mean and standard deviation were used to analyse the data. Non-parametric inferential statistic (chi-square) was used to compare the number of respondents differing on opinion. Alpha value was set at $p<0.05$.

\section{Results}

\subsection{Demographic Details of the Respondents}

Table 1. Educational qualifications of respondents

\begin{tabular}{lll}
\hline Qualifications & Frequencies & Percentages \\
\hline Primary school certificate & 38 & 15.8 \\
Secondary school certificate & 43 & 17.9 \\
Diploma certificate* & 48 & 20.0 \\
Bachelor degree & 37 & 15.4 \\
Masters degree & 15 & 6.3 \\
Doctorate degree & 11 & 4.6 \\
Others & 48 & 20.0 \\
\hline
\end{tabular}

*: Ordinary \& Higher diploma certificates 
One hundred and thirty four respondents $(55.8 \%)$ were male while $106(44.2 \%)$ were female. The educational qualification of are presented in table 1 . The diagnoses of the respondents are presented in table 2 .

Table 2. Diagnoses of respondents

\begin{tabular}{lll}
\hline Diagnoses & Frequencies & Percentages \\
\hline Burns & 4 & 1.70 \\
Fractures & 21 & 8.80 \\
Injection neuritis & 7 & 2.90 \\
Stroke & 84 & 35.0 \\
Osteoarthritis & 22 & 9.17 \\
Low back pain & 17 & 7.08 \\
Lumbar spondylosis & 6 & 2.50 \\
Cerebral palsy & 17 & 7.08 \\
Others & 46 & 19.16 \\
\hline
\end{tabular}

\subsection{Desires of Respondents on Current Medications}

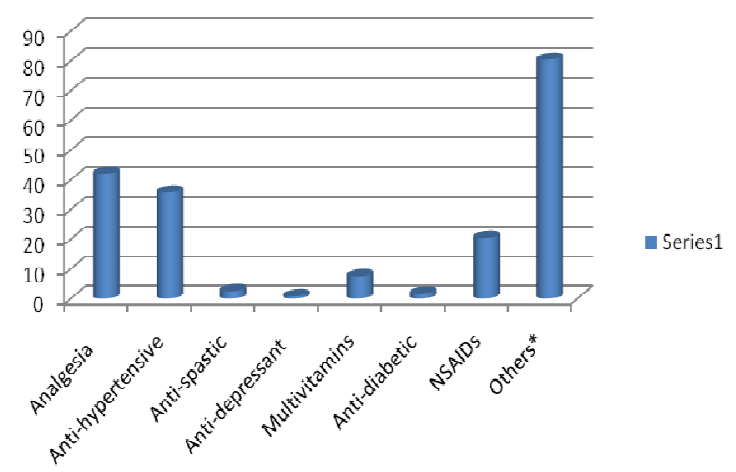

Figure 1. Current medication respondents

*other drugs such as anti-malarial, antibiotics, antacids and dietry supplements

One hundred and two (42.0\%), 49 (20.4\%) and $86(35.8 \%)$ respondents were placed on analgesia, Non-Steroidal AntiInflammatory Drugs and anti-hypertensive respectively. Other medications are represented in figure 1. One hundred and eighty two patients $(76.2 \%)$ were still on medications, the result of the chi-square showed that these number of respondents on medications was significantly higher than those who were not on any medication $\left(\mathrm{X}^{2}=65.38, \mathrm{P}<0.001\right)$. Similarly, a significant number of patients $[148(62.5 \%)$ wished to continue with taking the medications $\left(X^{2}=137.96\right.$, $\mathrm{P}<0.001)$. One hundred and ninety six $(82.0 \%)$ desired to continue with both oral medications and physiotherapy. Other responses on desires are presented in table 3.

One hundred and seventy four $(73.4 \%)$ respondents opined that prescription of drugs should not be the responsibility of medical doctors alone. The number of these respondents was significantly higher than those who opined otherwise $\left(\mathrm{X}^{2}\right.$ $=193.67, \quad \mathrm{P}<0.001)$. Majority [159 (69.7\%)] opined that physiotherapists would be most relevant at the chronic stage of diseases. The number of respondents who opined that prescription by physiotherapist should be at the chronic stage of disease was significantly higher than those who opined otherwise $\left(\mathrm{X}^{2}=35.53, \mathrm{P}<0.001\right)$. Other opinions are presented in table 4 . On reasons why they would provide such support, $142(94.7 \%)$ respondents perceived that such SP would provide opportunity for timely intervention for medications and $171(94.5 \%)$ opined that it would reduce burden on medical doctors. Other perceived benefits of SP are presented in tables 5 .

\section{Discussion}

In the last decade of health care modernization, there has been redrawing of professional boundaries and identities and greater workforce flexibility [1]. Several tasks and roles previously within the exclusive domain of medicine have been delegated to allied health professionals, with the reshaping of workforce to meet the challenges posed by changing demographic, social and political contexts [1].

Most patients supported inclusion of supplementary prescription into the roles of Nigerian physiotherapists and considering problem of litigation they opined that government enacts a law that will protect them. Crown report recommended that there should be a law guiding administration and supply of drugs within the confine of trained health professionals [3]. They also opined that prescription of drugs should not be the statutory responsibility of medical doctors alone if the aims of SP are to make health care provision comprehensive, more accessible and cost-effective. Doctors are currently the only recognized prescriber of drugs but patients in this study opined they should not be accorded that sole responsibility if Nigeria desired to meet the demands of modern clinical practice. In SP, doctors will still continue to play the leading role in drug prescriptions [22].

Table 3. Desires of respondents on current medications and physiotherapy

\begin{tabular}{|c|c|c|c|c|c|}
\hline Variables & & Frequencies & $\%$ & $\mathrm{X}^{2}$ & p values \\
\hline \multirow{2}{*}{ Still on medication } & Yes & 182 & 76.2 & & \\
\hline & No & 57 & 23.9 & 65.38 & 0.001 \\
\hline \multirow{2}{*}{ Desired to continue medication } & Yes & 148 & 62.5 & & \\
\hline & No & 89 & 37.6 & 137.96 & 0.001 \\
\hline \multirow{2}{*}{ Desired physiotherapy alone } & Yes & 90 & 37.5 & & \\
\hline & No & 150 & 62.5 & 15.00 & 0.001 \\
\hline \multirow{2}{*}{ Both physiotherapy \& medication } & Yes & 196 & 82.0 & & \\
\hline & No & 43 & 18.0 & 97.95 & 0.001 \\
\hline \multirow{2}{*}{ Drug modification by PT } & Yes & 203 & 84.9 & & \\
\hline & No & 36 & 15.1 & 116.69 & 0.001 \\
\hline \multirow{2}{*}{ Physicians to modify drugs } & Yes & 155 & 65.4 & & \\
\hline & No & 80 & 34.6 & 23.94 & 0.001 \\
\hline
\end{tabular}


The doctor's traditional authority to prescribe medicines alone could not be maintained because of emerging challenges facing health care services [23]. Although, they reported that the recent non-medical prescribing (supplementary prescribing) initiatives is being viewed erroneously as challenges to doctor's dominance. Nigeria will have to consider supplementary prescription by allied health professionals considering the increasing population and vast majority of Nigerians living in rural villages; and also increasing dependence on the already over-crowded health facilities in the urban cities.

Most respondent in this study were diagnosed to have stroke and musculoskeletal dysfunctions and this was the reason why analgesics, anti-hypertensives, muscle relaxants and NSAIDs are medications that most patients were taken at the time of this study; aside other drugs (anti-malarial, antacids, antibiotics and dietary supplements). Hence, if SP is allowed, these are the classes of drugs physiotherapist should be most likely allowed to prescribe. In the UK and Australasia, prescription right was given to musculoskeletal care physiotherapist while general right was given to podiatrist [24]. It was also opined that physiotherapists should be restricted to prescription for only chronic conditions. This corroborated the report of Department of Health in UK that supplementary prescribing is not suited for emergencies, urgent or acute prescribing situations because an agreed clinical management plan is needed before prescription [25]. Thus, acutely ill patients should be managed by the medical doctors.

Table 4. Opinion of respondents on drug prescriptions and SP

\begin{tabular}{|c|c|c|c|c|c|}
\hline Variables & & Frequencies & Percentages & $\mathbf{X}^{2}$ & P value \\
\hline \multirow{2}{*}{ Physicians alone should prescribe } & Yes & 63 & 26.6 & & \\
\hline & No & 174 & 73.4 & 193.67 & 0.001 \\
\hline \multirow{2}{*}{ Support Physiotherapists as SPs** } & Yes & 194 & 81.2 & & \\
\hline & No & 45 & 18.8 & 113.78 & 0.001 \\
\hline \multirow{2}{*}{ Support prescription policies } & Yes & 198 & 84.3 & & \\
\hline & No & 37 & 15.7 & 110.302 & 0.001 \\
\hline Combined therapy is effective & No & 20 & 8.4 & 357.15 & 0.001 \\
\hline \multirow{2}{*}{ Prescription enhances recovery*** } & Yes & 200 & 86.4 & & \\
\hline & No & 32 & 13.8 & 295.22 & 0.001 \\
\hline \multirow{2}{*}{ Prescriptions at chronic stage } & Yes & 159 & 69.7 & & \\
\hline & No & 69 & 30.3 & 153.44 & 0.001 \\
\hline Drugs alone are effective & Yes & 18 & 7.6 & & \\
\hline \multirow{2}{*}{ Physiotherapy alone is effective } & Yes & 66 & 27.9 & & \\
\hline & No & 171 & 72.2 & 46.52 & 0.001 \\
\hline
\end{tabular}

* The percentages are based on number of valid respondents to each question. ${ }^{*}$ SPs: Supplementary prescribers

*** Prescriptions by physiotherapists

It was recommended that supplementary prescription should be limited to prescriber's therapeutics and area of expertise [26]. Similarly, most respondents opined that supplementary prescribing will reduce waiting time in hospital, increase accessibility and will promote timely intervention for medications. The successful implementation of nonmedical (supplementary) prescribing had been reported to reduce patient's waiting time and had increased frequency of appointment in the UK [6], [27]. The opinion of our respondents did not differ from that of previous reports on effects of SP. Supplementary prescribing had been reported to reduce doctors' workloads and had also given them the opportunity to concentrate on patients with more complicated illnesses, requiring complex treatments and medications [21, 28]. Majority of respondents claimed that supplementary prescribing had lowered cost of management and this corroborated the reports of National Treatment Agency for Substance Misuse and Non-medical prescribing center that it had attracted substantial financial benefits through prevention of hospital admissions and secondary care referrals in the UK
$[6,29]$.

Most respondents were of the opinion that supplementary prescribing would likely enhance effective communication between patients and health care providers. There is paradigm shift in global health care services to share decision making where all stakeholders, patients inclusive, jointly develop clinical management plans. Most respondents found doctors reproaching, intimidating and impatient compared to SPs who were easier to talk to and were also more informal during conversation [29]. Other perceived benefit opined by most patients aside effective communication are likelihood of effective treatment plans and drug compliance; and these were not different from reports of previous studies [22].

In conclusion, patients in this study were of the opinion that Nigerian physiotherapists should be allowed to add supplementary prescription to their roles considering benefits like increased access to medical care, timely intervention for drugs granting opportunities for physicians to concentrate emergencies and critically ill patients. Also, an enactment should be made to protect them against litigations. They also 
opined that physiotherapists should focus on managing chronic conditions.

Table 5. Perceptions of respondents on benefits of supplementary prescription

\begin{tabular}{llll}
\hline Variables & & Frequencies & Percentages \\
\hline \multirow{2}{*}{ Timely drug intervention } & Yes & 142 & 94.67 \\
& No & 8 & 5.33 \\
Reduce burden on doctors & Yes & 171 & 94.48 \\
& No & 10 & 5.53 \\
Cost effective & Yes & 137 & 80.11 \\
Physicians re-focusing* & No & 34 & 19.88 \\
& Yes & 164 & 95.90 \\
Reduce waiting time & Yes & 170 & 4.09 \\
& No & 13 & 92.89 \\
Effective communication & Yes & 154 & 7.10 \\
Ease accessibility to & No & 15 & 91.12 \\
services & Yes & 157 & 8.86 \\
Improve effectiveness & No & 7 & 95.73 \\
& Yes & 161 & 4.27 \\
Improve drug compliance & No & 10 & 94.15 \\
& Yes & 136 & 5.85 \\
\hline
\end{tabular}

* Physicians shift focus to complex diseases

\section{References}

[1] Borthwick Alan M, Anthony J Short, Susan A Nancarrow, Rosalie Boyce (2010). Non- medical prescribing in Australasia and the UK: the case of podiatry. J Foot Ankle Res. 2010; $3: 1$.

[2] Royal Australian College of General Practitioner (RACGP). The RACGP Curriculum for Australian General Practice. Multidisciplinary care (2011). http://curriculum. racgp.org.au/statements/multidisciplinary-care/. Accessed on $20^{\text {th }}$ June 2014.

[3] Crown report (1999). Review of prescribing, supply \& administration of medicines. Final Report April 2000 Secretary of State for Health Room 407, Richmond House 79 Whitehall London SW1A 2NS. $\mathrm{http}: / /$ webarchive.nationalarchives.gov.uk/ 20130107105 354/http:/www.dh.gov.uk/prod_consum_dh/groups/dh_digital assets/@dh/@en/documents/digitalasset/dh_4077153.pdf. Accessed on $18^{\text {th }}$ June 2014.

[4] Brown JB, Stewart MA, McCracken E, et al (1986). The patient-centred clinical method, 2: definition and application. Fam Pract. 1986;3:75

[5] National Health Services (2010). A safe prescription: Developing nurse, midwife and allied health profession (NMAHP) prescribing in Scotland. http://www. nes.scot.nhs. uk/media/555947/a safe_prescription_progress_report_2010.p df. Accessed on $20^{\text {th }}$ June 2014.

[6] National Treatment Agency for Substance Misuse (2007). Non-medical prescribing, patient group directions and minor ailment schemes in the treatment of drug misusers. www.nta.nhs.uk. Accessed on $18^{\text {th }}$ June 2014.

[7] Health Sciences (2014). Our role in the non-medical prescribing revolution. University of Southampton.http://www.southampton.ac.uk/healthsciences/b usinesspartnership/services/ nonmedicalprescribing. Accessed on $20^{\text {th }}$ June 2014.

[8] Safran DG, Taira DA, Rogers WH, et al (1998): Linking primary care performance to outcomes of care. J Fam Pract. 1998; 47: 213-220.

[9] Heisler M, Bouknight RR, Hayward RA, Smith DM, Kerr EA (2002). "The relative importance of physician communication, participatory decision making, and patient understanding in diabetes self-management". J Gen Intern Med 17 (4): 243-52.

[10] Hibbard JH, Mahoney ER, Stock R, Tusler M (2007). Do increases in patient activation result in improved selfmanagement behaviors. Health Serv Res 42 (4): 1443-63. doi:10.1111/j.1475-6773.2006.00669.x. PMC 1955271. PMID 17610432 .

[11] Lewin SA, Skea ZC, Entwistle V, Zwarenstein M, Dick J (2002): Interventions for providers to promote a patientcentred approach in clinical consultations. (Cochrane Review). In: The Cochrane Library, Issue 1. Oxford: Update Software. Available http://www.mrc.ac.za/policybriefs/1 polbrief2002.htm [Accessed 10 May 2014].

[12] Höglund AT, Winblad U, Arnetz B, Arnetz JE (2010). "Patient participation during hospitalization for myocardial infarction: perceptions among patients and personnel". Scand J Caring Sci 24 (3): 482-9. doi:10.1111/j.1471-6712.2009.00738.x. PMID 20230518.

[13] Julia M. Hush, Kirsten Cameron and Martin Mackey Therapy Care (2010): A Systematic Review Patient Satisfaction with Musculoskeletal Physical November 11, 2010 Phys Ther. 2011; 91:25-36.

[14] Salisbury and Sullivan (1998). Clinical decision making planning effective treatments. In O'Sullivan SB, Schmitz TJ (eds). Pkysical Rehabilitation Assessment and Treatment, 4th ed. Philadelphia, PA, Davis, 2001, pp 1-7.

[15] Health and Care Professions Council (2014). Post-registration programmes. Approval visit reports.http://www.hpcuk.org/education/programmes/approval reports/index.asp $? \mathrm{id}=688 \&$ ep $=64$

[16] Onigbinde Ayodele, Solomon S. Adereni Adebiyi, Kayode D.S Bamitale, S.V.K. Kambalametore, Vyvienne M'kumbuzi, Wazakili Margaret (2013). Changing the prescription status of physiotherapy. Nigeria journal of Medical Rehabilitation, Vol. 16, No 2. Available at http://www.njmr.org.ng. Accessed on 17 June 2014.

[17] 17] Ojo Ayodele Mojisola (2014). Opinion of pharmacists on the enlistment of physiotherapists as supplementary prescribers of relevant medications. An unpublished dissertation of the department of Medical Rehabilitation department of Obafemi Awolowo University, Ile-lfe, Osun State, Nigeria.

[18] Onigbinde AT, Olaogun MOB, Irogue K (2012). An evaluation of the knowledge level of Nigerian Physiotherapists on topical pharmacotherapy Hong Kong Physiotherapy Journal, Vol. 1 Pgs 1-7.

[19] Department of Health, Social Services and Public Safety (DHSSPS) (2004). Best Practice Guidance for Supplementary Prescribing by Nurses within the HPSS in Northern Ireland DHSSPS. 
[20] Mathers Nigel, Nick Fox, Amanda Hunn (2009). Surveys and Questionnaires. The NIHR Research Design Service for Yorkshire \& the Humber. www.rds-eastmidlands.nihr.ac.uk

[21] García de Yébenes Prous M. Jesús, Francisco Rodríguez Salvanés, Loreto Carmona Ortells (2009). Validation of questionnaires. Reumatol Clin. 2009;5 (4):171-177.

[22] Bissell Paul, Richard Cooper, Louise Guillaume, Claire Anderson, Anthony Avery, Allen Hutchinson, Veronica James (2008): An Evaluation of Supplementary Prescribing in Nursing and Pharmacy Final Report for the Department of Health October 2008. http://eprints.whiterose.ac.uk/76239/1/Supplementary_prescri bing.pdf. Accessed on 19th June 2014.

[23] Cooper. Richard J, Paul Bissell, Paul Ward, Elizabeth Murphy, Claire Anderson, Tony Avery, Veronica James (2011). Further challenges to medical dominance? The case of nurse and pharmacist supplementary prescribing. University of Sheffield, Regent Court, 30 Regent Street, Sheffield, S1 4DA, UK. Email: richard.cooper@sheffield.ac.uk

[24] Borthwick A (2001). Drug prescribing in podiatry: Radicalism or Tokenism?Brit J Podiatr. 4: 56-64.

[25] Department of Health (2005). Supplementary Prescribing by
Nurses, Pharmacists, Chiropodists/Podiatrists, Physiotherapists and Radiographers within the NHS in England: A guide for implementation Available at: http://webarchive.nationalarchives.gov.uk/ 20130107105354/http://www.dh.gov.uk/prod consum dh/gro ups/dh_digitalassets/@dh/@en/documents/digitalasset/dh_411 0033.pdf. Accessed 25 November, 2013.

[26] Stephensons Terence (2000). Implications of the Crown's report and nurse prescribing. Arch Dis Child, (6)83: 199 - 202

[27] Royal college of nursing (2012). RCN Fact Sheet. Nurse Prescribing in the UK. Policy and International Department. http://www.rcn.org.uk/ data/assets/pdf/Nurse Prescribing_in_the_UK_-_RCN_Factsheet.pdf. Accessed 25 November, 2013.

[28] Scottish Executive Health Department (2003). Scottish Executive Health Department (2003): Supplementary Prescribing by Nurses within NHS Scotland (C) Crown copyright 2003

[29] Non-medical prescribing center (2005). Improving mental health services by extending the role of nurses in prescribing and supplying medication: Good Practice Guide. London: National Prescribing Centre, National Institute of Mental Health, Department of Health. 